\title{
4D GIS FOR MONITORING RIVER BANK EROSION AT MEANDER BEND SCALE: CASE OF MOSELLE RIVER
}

\author{
M. Koehl ${ }^{1, *}$, G. Piasny ${ }^{2}$, V. Thomine ${ }^{1}$, P-A. Garambois ${ }^{3}$, P. Finaud-Guyot ${ }^{4}$, S. Guillemin ${ }^{1}$, L. Schmitt ${ }^{2}$ \\ ${ }^{1}$ ICube Laboratory UMR 7357, INSA Strasbourg, France \\ \{mathieu.koehl, valentin.thomine, samuel.guillemin\}@insa-strasbourg.fr \\ ${ }^{2}$ University of Strasbourg - LIVE (Laboratoire Image, Ville, Environnement) UMR 7362 - CNRS - Unistra - ENGEES, France \\ \{guillaume.piasny, laurent.schmitt\}@unistra.fr \\ ${ }^{3}$ IRSTEA, Aix-en-Provence, France. pierre-andre.garambois@irstea.fr \\ ${ }^{4}$ HydroSciences Montpellier, Polytech Montpellier, Montpellier, France. pascal.finaud-guyot@umontpellier.fr
}

KEY WORDS: Morphodynamic monitoring, diachronic analysis, geodetic surveying, photogrammetry, UAV, 4D GIS.

\begin{abstract}
:
The "Wild Moselle" regional nature reserve extends over $13 \mathrm{~km}$ at the western foothills of the Vosges Mountains (France). The hydrological regime of the river is characterized by high flow in winter and spring and low flow in summer. Its average slope is 0.12 $\%$ and its average bankfull width is $60 \mathrm{~m}$. The coarse sediment load comes mainly from bank erosion. Although this sector is relatively less affected by past or present human activities, the propagation of morphodynamic adjustments initiated by actions carried out both upstream and downstream of this sector impacts the current functioning of the river. These erosion waves converge today towards the central part of the reserve, which led to the collapse of the central pier of the Bainville-aux-Miroirs bridge during a 2-year flood in 2011, and could induce potential risks of defluviation which may destabilize infrastructures. In this context, the study carried out aims to characterize and anticipate the morphodynamic evolutions of the Moselle to be able to propose scenarios of management and restoration of the lateral mobility of the river. For this purpose, a 2D hydro-sedimentary model is being built over the entire reserve, combined with a detailed morpho-sedimentary monitoring. In order to improve the understanding of the lateral migration of the Moselle River, a photogrammetric monitoring was carried out along the concave bank of the most active meander of the studied sector. To follow this morphological evolution more closely, it was decided to establish a 4D GIS. The objective of this monitoring is to compare the rate of bank retreat with hydrodynamic parameters in order to estimate the geotechnical properties of the bank. Comparison of the observed and modelled bank retreat must thus allow these different parameters to be calibrated in the hydro-sedimentary model. As part of this work, this paper aims to highlight the use of 4D GIS to monitor bank retreat at the scale of a meander bend and is divided into three different parts: (i) a state of art to situate the study into the current knowledge and technologies, (ii) a presentation of the study area and the measurements carried out and (iii) a description of the different 3D or 4D data produced and the consequent spatial analyses.
\end{abstract}

\section{INTRODUCTION}

Data management and representation have made great progress last decades notably in moving from 2D to 3D and integrating time. This type of representation has developed considerably in the world of geo-information, mainly because of the evolution of processing and visualization algorithms but also thanks to the multiplication of survey techniques. As a result, it becomes easier and easier to model a portion or even a territory in 3D. Two technologies play a major role in these developments: laserscanning and photogrammetry.

Pfeifer (2007) defines terrestrial laser scanning as a data acquisition technique using laser light to directly measure, in a regular frame, the coordinates of $3 \mathrm{D}$ points on surfaces at an Earth position. A 3D terrestrial laser scanner (TLS) is a device that uses this process to determine $\mathrm{X}, \mathrm{Y}$ and $\mathrm{Z}$ points coordinates in order to acquire a point cloud of the area. Laser-scanning of an area using a laser scanner, whether terrestrial or aerial, provides 3D point clouds of the entire area with a configurable point density depending on the equipment and the recording conditions.

The other technique implemented to obtain 3D models, is based on photogrammetry from images that can also be aerial, from UAV, or terrestrial. Aerial photography has long been used for mapping applications. Many applications result from it. One of its main advantages is the minimization of field work. Photogrammetry has now become a widely used technique even for local scale mapping applications. This technique allows the user to obtain 3D data from an area of interest. It is also used to produce orthophotos. Photogrammetry has also experienced a new boom with the development of the use of UAVs (unmanned aerial vehicles) for mapping, particularly on a larger scale. Photogrammetry by UAV is particularly interesting in sites requiring rapid intervention, including the case of inspection and monitoring (Murtiyoso et al., 2017) (Jaud et al., 2014). It is therefore possible, from images with well-defined overlapping areas, to determine the relief and contours of an object or territory in the form of point clouds obtained from dense matching techniques.

Digital Terrain Models (DTM) and Digital Surface Models (DSM) are used as digital representations of the natural terrain. Such acquisitions can be made several times under the same conditions and with sufficient precision to be compared. The multi-temporal data also allow to display local changes in topography. Indeed, by comparison with a reference model, topographic and/or height changes can be quantified and represented. This was used to evaluate the accuracy of digital surface model (DSM) of river-channel morphology derived from

\footnotetext{
${ }^{*}$ Corresponding author
} 
the imagery acquired with a low-cost digital camera on board an unmanned multi-copter (Watanabe and Kawahara, 2016). Crosssections make it possible to highlight in a very explicit way these topographical evolutions. The DTM/DSM generated directly from the point cloud is an ideal support to analyze morphological evolutions in some cases and estimate sediment budgets (Eschbach et al., under review; Rivas Casado et al., 2017). By combining the DTM and aerial photographs, it is also possible to produce georeferenced orthophotos that can be integrated into the 4D GIS and serve as additional support for analysis, especially on smaller scales (Dawod et al., 2014). The advantages that UAVs can provide for the survey of small areas, as meander bends, are however very interesting. UAVs are alternatives to quickly recording data (images) to compute a 3D model of a small area. In fact, UAVs show the advantage of being inexpensive, whether in financial or human terms, and their size and weight make them easy to deploy and implement.

Considering these advantages, a photogrammetric monitoring using UAV was carried out along the concave bank of the most active meander of the Moselle River in order to better understand and model the lateral migration of the river. In order to survey this fluvial morphodynamic process more closely, a 4D GIS has been established along the meander bend. The objective of this monitoring is to assess the bank erosion rates according to hydrodynamic parameters (discharges, water levels, flow velocities, shear stresses, etc.) and geotechnical properties of the eroded bank (rest angle, bank sediment stratigraphy, vegetation, etc.). Subsequently, comparison of observed vs modelled bank retreat should allow calibrating the geotechnical parameters into a 2D hydro-sedimentary model. This paper is divided into three parts which: (i) describe steps from photogrammetric monitoring to point of clouds construction, (ii) present a method to extract bank profiles and (iii) show how to integrate photogrammetric data into a GIS also including other topo-bathymetric data.

\section{STUDY SITE}

The Moselle River drains a catchment area of $1976 \mathrm{~km}^{2}$ from its source at Bussang in the Vosges Mountains to Tonnoy at the Lorraine plateau. The "Wild Moselle" regional nature reserve extends over $13 \mathrm{~km}$ at the western foothills of this massif. The river's hydrological regime is characterized by high flow in winter and spring and rather low flow in summer. Its average slope is $0.12 \%$ and its average bankfull width is $60 \mathrm{~m}$. The load originates quasi-exclusively from bank erosion. Although this sector is relatively less affected by local past or present human activities (bank stabilization, river bed gravel extraction, floodplain gravel mining, etc.), the propagation of morphodynamic adjustments initiated by actions carried out both upstream and downstream this sector impact the current functioning of the river: regressive and progressive erosions that can foster strong lateral erosion, meander cutoff, channel contraction, etc. So the waves of both regressive and progressive erosion converge today towards the central part of the reserve, which led to the collapse of the central pier of the Bainville-auxMiroirs' bridge during a 2-year flood in 2011. These dynamics could also induce a potential risk of avulsion which may destabilize other infrastructures along the studied river reach. In this context, the underway study aims to characterize and anticipate morphological evolutions of the Moselle River to be able to propose scenarios of management and restoration of the lateral mobility of the river. To reach this purpose, a 2D hydrosedimentary model is being built over the entire natural reserve, which is combined with a detailed morpho-sedimentary monitoring. This consists in topo-bathymetric LiDAR data, hydrological surveys (limnimeters, ADCP - Acoustic Doppler Current Profilers), and morpho-sedimentary surveys (sediment tracking - 2500 pit-tags, grain size measurements on both surface and subsurface).

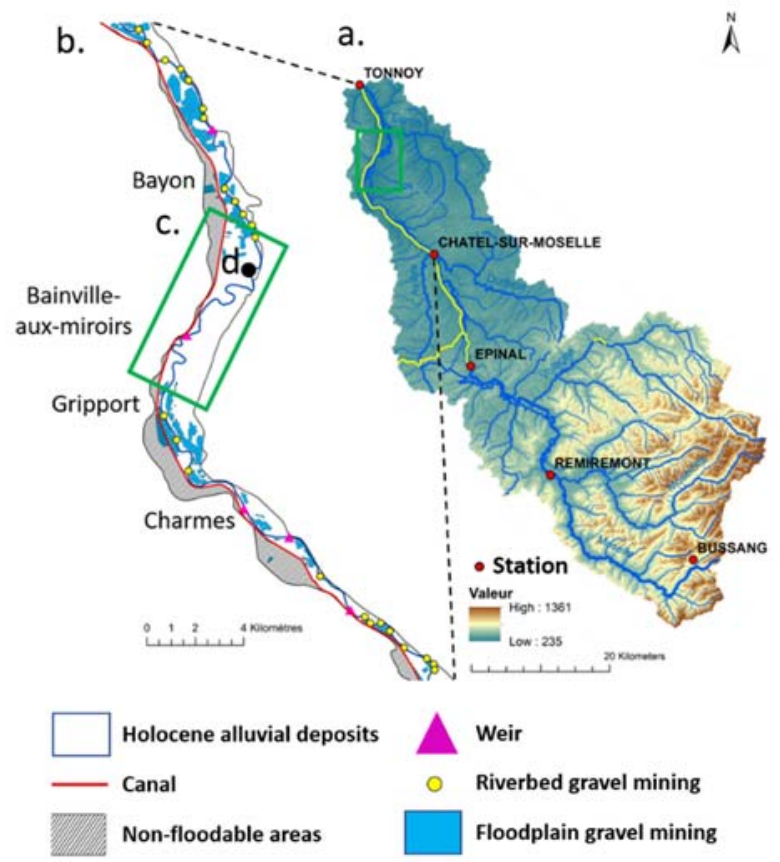

a. Catchment of the Moselle River upstream Tonnoy

b. Valley bottom of the Moselle River from Châtel-sur-Moselle to Tonnoy

c. "Wild Moselle" Regional naturel reserve and

d. Studied meander bend

Figure 1: Study site location.

\section{BANK SURVEY}

\subsection{From UAV photogrammetric data acquisition to point} clouds

To highlight the evolutions of the banks of the Moselle, it is necessary to be able to compare topographical data at different dates. In order to obtain results showing significant changes, it was decided to acquire data after each morphogenic flood, when the water level was low enough to characterize the complete bank profile, from the bank top to the bank toe. As shown in Figure 4, several floods occurred during 2018-19. For accessibility, timing and organization reasons, four dates were chosen for the recording of in situ data. As previously defined, it was decided to test the acquisition of photogrammetric data using a DJI Phantom 3 UAV. The covered area consisted in the concave bank for a length of about $700 \mathrm{~m}$.

Following the classic considerations (Remondino et al., 2011), a typical image-based surveying with UAV systems requires a mission planning, GCPs measurement for geo-referencing, image recording, camera calibration, and image orientation, image processing for 3D modeling and information extraction.

The first date was an experimental operation to define the first state of the meander and to calibrate the field operations.

More than 1,000 images (Table 1) were recorded during each mission, whether in nadiral or oblique views (Figure 2). On some of them, coded circular targets are visible. These were used to materialize GCPs (Figure 3): the GCP coordinates were then measured with a geodetic GNSS receiver. The measured and automatically extracted points using Agisoft Metashape software are in the centre of the targets and their coordinates have been determined in the French RGF93-CC49 system. 
The flight plan was executed manually. As authorized in France for visual drone flights, it consisted of several $300 \mathrm{~m}$ long areas. Each areas was recorded in multiple passages with nadiral views and several passages with oblique views at $30^{\circ}$ and $60^{\circ}$, perpendicular to the bank or inclined by $30^{\circ}$. The overlapping of the successive photos is about $60 \%$. The flight time of about twenty minutes made it possible to make these shots without problems. The shooting trigger was set to automatic shooting at $2 \mathrm{~s}$. The height of the flight was between 20 and 40 meters which allowed to obtain a pixel size of $1 \mathrm{~cm}$.

Limnimeters have also been located upstream and downstream of the meander in order to records water heights during the studied periods.
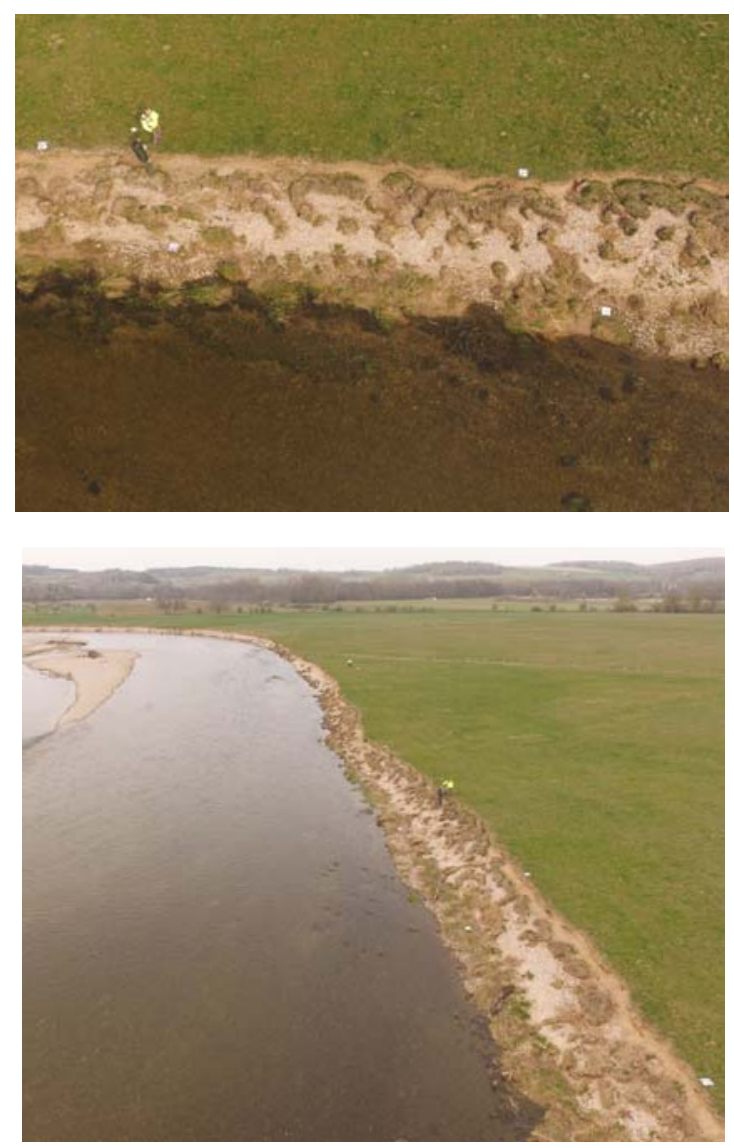

Figure 2: Nadiral (top) and oblique (down) images of the studied bank.

\subsection{Generation of point clouds.}

Large quantities of images were therefore acquired by drone for each measurement campaign. Among this mass of data for each campaign, a sorting was carried out, to preserve only images with a good quality.

Two selection methods were applied: (i) a qualitative selection apparent to a visual analysis of the images to eliminate the unusable images (duplicates, under or overexposed images). In this first method, the operator's analysis is heavily used to make a manual selection; (ii) a quantitative selection using the Metashape software to estimate the quality of an image, by means of a coefficient. A blurry image, therefore unusable, will have a coefficient of 0.50 . To maintain only good quality images, the acceptability threshold for this coefficient has been set at 0.75 . Table 1 shows the number of images acquired and the number finally used in processing, corresponding to a ratio from about 50 to $80 \%$. In the end, the selection was a little harsher for the first and third acquisition campaign because of the weather conditions (very hot sunshine). Nevertheless, the number of photos used was sufficient to meet the overlay criteria.

\begin{tabular}{|c|c|c|c|c|}
\hline Date & \# images & \# used images & ratio & \# Chunks \\
\hline $05 / 03 / 2018$ & 1443 & 835 & 0.58 & 5 \\
\hline $26 / 03 / 2018$ & 1302 & 1015 & 0.78 & 2 \\
\hline $12 / 02 / 2019$ & 1145 & 620 & 0.54 & 6 \\
\hline $03 / 04 / 2019$ & 1179 & 865 & 0.73 & 7 \\
\hline
\end{tabular}

Table 1: Images used

The UAV used to take pictures of the meander was a DJI Phantom 3 pro multi-copter. This device has the advantage of being light and easy to handle. It has its own positioning system (GNSS) which gives the position of the drone at each image recording with a quasi-metric accuracy. However, this relative inaccuracy has been a disadvantage in the calculation of precise camera locations since the software relies on these initial values. Consequently, the coordinates available in the metadata (Exif) of the images were not used.

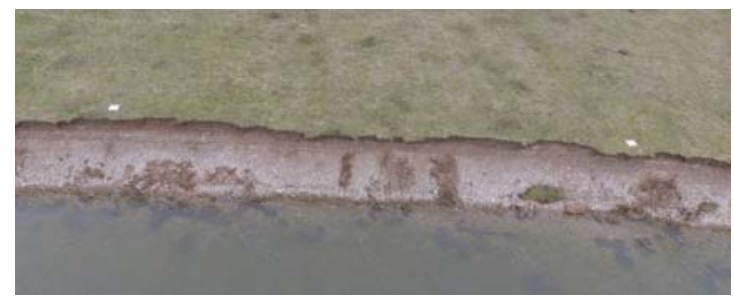

Figure 3: Bank morphology and coded targets as GCPs

\subsection{Identification and visualization of GCPs in a GIS}

As the length of the studied meander is quite substantial, the number of available coded targets for georeferencing was too low. These were therefore reused several times using the same cut-out as allowed by the maximum flight distances. The targets were renamed and matched thanks to their location in a GIS layer (Figure 4).

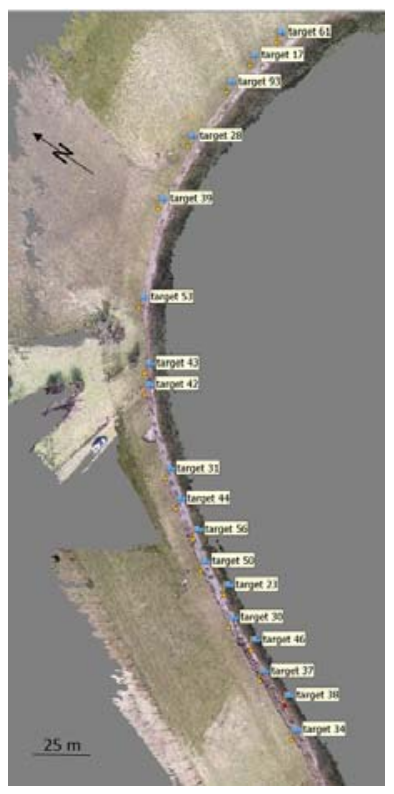

Figure 4: GCPs in GIS layer 


\subsection{Creation of the point clouds}

For organizational reasons, each model was divided into chunks, treated separately, and then merged into a single point cloud per campaign. The different processing steps followed a classic photogrammetric process: (i) relative orientation of the images Align Photos - to move from image coordinates to model coordinates from which a sparse point cloud can be generated. This was done through the automatic extraction of key points in each image which are then paired with the key points of neighboring images to generate tie points. Sfm (Structure from motion) algorithms then allowed the calculation of the relative orientation of the images from which was deduced a 3D point cloud; (ii) georeferencing of the point cloud thanks to the GCPs imported and detected automatically (markers) thanks to the coded targets - Optimize Camera -. The accuracy of the different obtained 3D models was about 2-3 cm; (iii) another adjustment was undertaken, but this time to check the criterion of accuracy. Some GCPs were transformed into check points. Errors on check points were always greater than errors on GCPs which denotes an existence of a systematism that could be explained by a pixel size larger than the precision of the coordinates. However, we get an accurate model. The next step is the generation of the dense point cloud - Build Dense Cloud -. At this level, the software increases the amount of points by densifying the cloud from the images. Densification quality parameters can be set at this stage. The number of points in high quality is, for example, four times higher than that obtained by placing the parameter at Medium (for example, for a band of $700 \mathrm{~m}$ long over a depth of $30 \mathrm{~m}, 4.4$ million and 1.1 million of points, respectively). Last step was to clean out the unnecessary noises and points and reduce the model to a $10 \mathrm{~m}$ strip around the bank. After this stage, 4 georeferenced 3D point clouds, denoised and cleaned were available for analysis and interpretation (Figure 5).

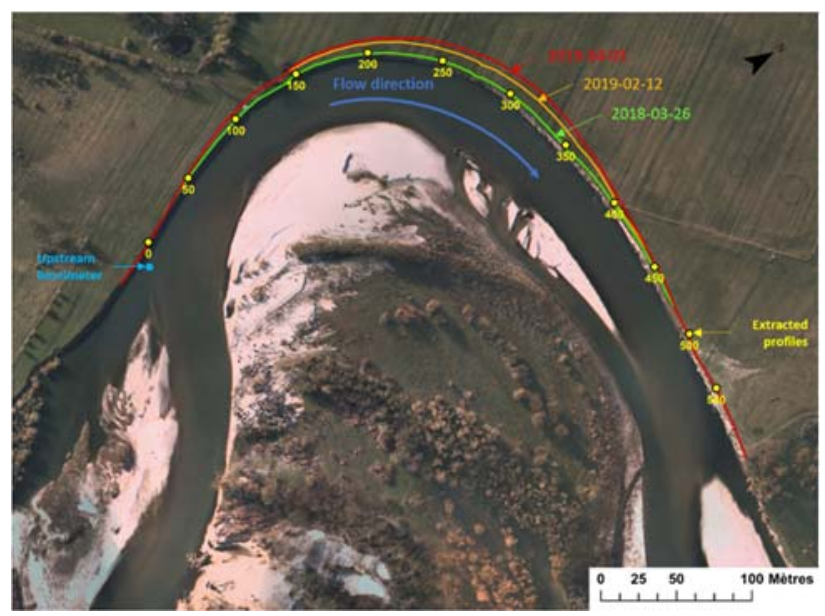

Figure 5: Planimetric evolution of the meander bend during the studied period

\subsection{Profile extraction}

From these point clouds, it was possible to analyze the erosion of the banks over time, and in particular the impact of each flood. The best way to show the planimetric evolution was to directly compare the four point clouds. For this we used the CloudCompare software package, which is a tool allowing comparison of point clouds. This analysis is intended to identify areas of high and low bank retreat. The interoperability between Metashape and CloudCompare was achieved through the LAS or OBJ formats. LAS is a file format designed for the interchange and archiving of LiDAR point cloud data. It is an open, binary format specified by the American Society for Photogrammetry and Remote Sensing (ASPRS). The format is widely used and regarded as an industry standard for LiDAR data. From our field observations, we expected significant deviations (in the order of several meters). Despite CloudCompare is an adequate tool to distinguish changes between two nearby point clouds (for example, for auscultation), but was not efficient in our case. We therefore used the overlay of georeferenced point clouds to quantify the bank erosion.

It was then necessary to analyze the bank evolutions with another medium to have more information about it. The realization of cross-sections is an interesting option, but only with a $2 \mathrm{D}$ view (in this case $\mathrm{x}$ and $\mathrm{z}$ ). Metashape does not offer tools to directly calculate profiles. For this reason the data were exported and superimposed in 3DReshaper software package. The realization of cross-sections required the definition of an axis according to which these were to be calculated. For such needs, all point clouds have to rasterized in CloudCompare with a grid size of 1 $\mathrm{m}$, when local slopes were calculated using ArcGIS package. Based on slope discontinuity, a line was drawn along the river banktop for each campaign, from the limnimeter to the downstream opposite side. Considering that profiles were built perpendicularly to the banktop line, this line was smoothed using Bezier curves tools, in order to estimate as far as possible vertical profiles. The reference line chosen to build profiles was the banktop line of the first acquisition. Vertical profiles were automatically extracted each $10 \mathrm{~m}$ using 3DReshaper software with a section thickness of $0.1 \mathrm{~m}$ and a maximal edge distance of $0.5 \mathrm{~m}$. Profiles were extracted from 0 to $540 \mathrm{~m}$ which corresponds to the overlapping area between all surveys. The profiles length of $15 \mathrm{~m}$ is constant and corresponds to the observed maximal bank retreat.

Extracted profiles were manually cleaned in Autodesk in order to remove points corresponding to vegetation and smooth the bank profiles. Each cleaned 2D lines was saved as DXF AutoCAD file and a Matlab program was developed in order to automatically open these files and superimpose them (figure 6).

The stratigraphical limit between the fine and coarse sediment layers was visually defined using point cloud textured 3D model of the first survey, because the image brightness allowed to identify both layers.

The elevation of this limit was supposed to be constant during the surveying period.

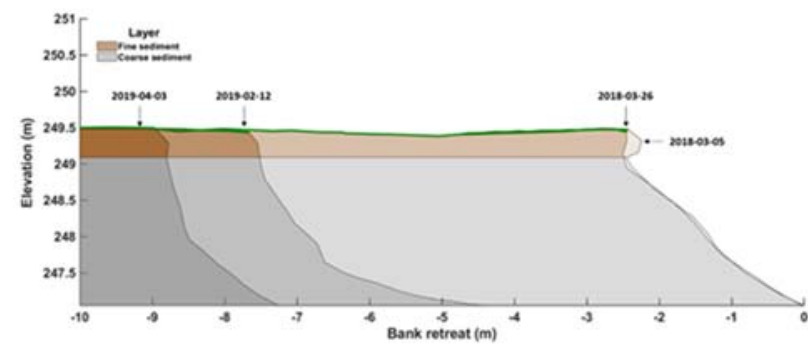

Figure 6: Bank retreat observed at $220 \mathrm{~m}$ from 2020-03-26 to 2019-04-03

Submerged data was however not exploitable in the sense that it was highly noisy, due to the reflection of water and the change of medium. Therefore, to be consistent, each profile was cut off at the elevation corresponding to the highest water level being observed during all of the surveys. In fact, water levels of the first and last surveys were relatively low and similar, but the water level of the third survey was 60 to $70 \mathrm{~cm}$ higher. Thus, the water level measured during this campaign was used as lowest 
reference. This shows the importance to collect data during low flow in order to dispose of the most complete bank profile. But, as indicated in figure 7 , available survey windows were restricted over the year and especially during the spring and the winter.

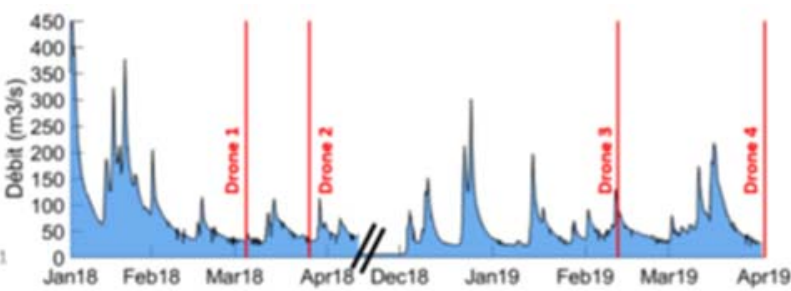

Figure 7: Hygrogram recorded during the studied year

\section{DIACHRONIC PROFILE ANALYZES}

Areas under each bank profile (figure 6) were calculated in Matlab and the eroded surfaces were deduced by subtracting values obtained between each survey. As the bank height varied along the meander bend, each bank profile was normalized, in order to be able to compare the surface eroded between profiles extracted at different locations. Therefore, for each profile, the banktop elevation was considered as $1 \mathrm{~m}$, while the bank toe elevation was considered as $0 \mathrm{~m}$. Thus, if between two surveys, the bank retreated of $1 \mathrm{~m}$ and the shape of the both bank profiles was constant, the calculated eroded surface equals $1 \mathrm{~m}^{2}$. For each profile, eroded areas were cumulated and represented in figure 8. There are no values at $400 \mathrm{~m}$ because of the presence of a tree, which felled into the channel during the study. Finally, in order to compare the observed eroded areas to the observed retreats of the banktop, a Matlab program was developed to automatically identify banktop positions along the profiles. Banktop retreats of the first studied flood were not represented because the banktop positions were nearly identical.

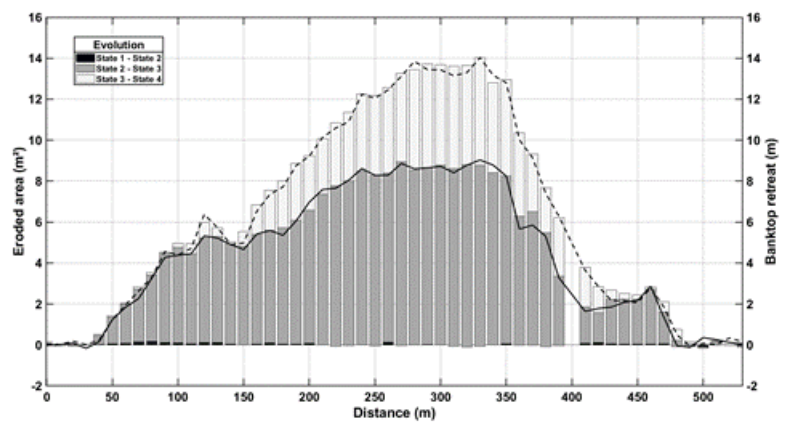

Figure 8: Cumulative normalized eroded areas (diagrams) and corresponding banktop retreats (curves)

Results show that concave bank of the meander bend was barely eroded between the first and the second surveys corresponding to an unique flood that occurred in March 2018. This means that bank erosion threshold lies close or above to a discharge of approximately $120 \mathrm{~m}^{3} / \mathrm{s}$. Comparison between second and third surveys shows that bank erosion of the meander bend started at $30 \mathrm{~m}$ and ended at $500 \mathrm{~m}$ (fig. 9). Maximal bank retreats were observed between $240 \mathrm{~m}$ and $350 \mathrm{~m}$ with an average value of -8 $\mathrm{m}$. On the whole, the plan view of the observed bank retreat is oval shaped, with discontinuities located around $150 \mathrm{~m}$ and 400 $\mathrm{m}$. Between $120 \mathrm{~m}$ and $150 \mathrm{~m}$, the thickness of the fine sediment layer reached $1 \mathrm{~m}$ to $1.5 \mathrm{~m}$, while this value was about $0.4 \mathrm{~m}$ to $0.5 \mathrm{~m}$ along the whole meander. This stratigraphic variation of the bank profile is due to the presence of a paleochannel that was filled by fine sediments over the time. Another paleochannel was also visible at $270 \mathrm{~m}, 350 \mathrm{~m}$ and $410 \mathrm{~m}$, but with a reduced width (5-10 m) and depth (0.6-0.8 m). However, the erodibility of the fine sediment layer is lower than this of the gravel layer, due to cohesion forces. Thus, the presence of former channels into the concave bank controls the bank retreat rate, and more generally the current morphodynamics of the meander (Eschbach et al., under review).

Furthermore, bank retreat discontinuities observed at $150 \mathrm{~m}$ and $400 \mathrm{~m}$ are also due to the presence of a road that was eroded during 2011 and which currently continues to be eroded (figure 5). Along this road some trees are now located close to the banktop and their roots now enhance the bank stability. However, at $400 \mathrm{~m}$, it is no longer the case as shown by the comparison between the third and the fourth surveys. During the two last survey periods, observed bank erosions were concentrated in the center part of the meander bend, but were slightly higher in the downstream part of the meander bend. Maximal bank retreat was in average $14 \mathrm{~m}$ which results in a total bank erosion of $14 \mathrm{~m}$ during the last survey period. Globally, banks were stable at the beginning and the end of the meander bend due to low hydraulic conditions and also because they were stabilized by vegetation, blocks and/or fine sediments.

\section{INTEGRATION OF PHOTOGRAMETRIC DATA INTO GIS AND COUPLING WITH BATHYMETRIC DATA}

The point cloud extracted from the last photogrammetric campaign was combined with a bathymetric survey in order to study the development of the meander bend. Bathymetric data were collected using an acoustic Doppler current profiler (ADCP) coupled with an accurate differential GPS (DGPS). Recorded water depths were associated to DGPS coordinates during the post-processing via timecode according to a time step of 1 second. Field measurements were carried out after the photogrammetric campaign at higher water levels to have an overlay between both datasets and facilitate point clouds merging. The boat trajectory followed a zigzag path from one side to the other side of the river to optimized the river bed mapping and simplify interpolation between each transects. Some longitudinal profiles were also carried over the thalweg and along both river banks to complete this dataset and characterize the maximum lateral extension of the river bend. However, longitudinal extension of the bathymetric survey was reduced to the central part of the meander compared to photogrammetric surveys due to riffles located at each bend inflection which prevents taking measurements from a boat. Moreover, as the water levels were low during the survey, acoustic beams were concentrated in a small area and lateral beams did not improve the river bed mapping. Therefore, only the vertical beam was used to map the meander bend bottom. These bathymetry points were interpolated using a Triangular irregular networks (TIN) available in ArcGIS software. Edges of the TIN were manually adjusted in order to connect nodes between transects according to flow paths. Some bathymetry outlier points were delete as well during the TIN construction. Meanwhile, image-based point clouds was rasterized in CloudCompare, with a grid size of $1 \mathrm{~m}$, to be consistent with the LiDAR resolution. This raster was converted to points and points were added to the previous TIN. During these steps, data resolution was altered by averaging elevation of points contained in cells, but this process is considered as negligible at the scale of our study. Results may however be affected by this approach in case of over-hanging riverbanks, in this instance cantilevered bank profile are replaced by a vertical wall throughout 
rasterization. As shown in this study, the cantilever is not the main bank failure mechanisms along the meander bend, which justifies the method we used. Likewise, this data are integrated in a 2D mesh and modelling results will be compared to a topobathymetric LiDAR. So, the bank retreat of the basal layer will not be investigated here.

Furthermore, before merging photogrammetric and bathymetric point clouds, underwater points were deleted from the imagebased dataset. Indeed, elevation accuracy of underwater points was difficult to estimate without underwater ground control points at the time of the survey. However, the influence of refraction on underwater three-dimensional reconstruction may be estimated, but this may also be affected by the water turbidity. Considering that turbidity varied from one campaign to the other, integration of underwater points did not seem relevant as a quick and easy way to study bank retreat. In fact, most surveys were carried out with a water level below the bank toe. So, all the bank profiles were characterized satisfactorily. At the end of the data processing, the TIN model including concave bank and river bed was converted to a raster with a grid size of $1 \mathrm{~m}$.

Comparison between bathymetric surveys and LiDAR topobathymetric acquisition shows an average offset of $9 \mathrm{~cm}$ of the river bed elevation all over the reserve. Although absolute elevation of photogrammetric and bathymetric data is supposed to be more reliable than LiDAR data, it was more convenient to shift the elevation of the raster over the meander bend than over the whole river reach. Indeed, as part of this study, monitoring of morphological evolution of the river bend allows to use relative elevations.

Finally, both meander and LiDAR raster were superimposed and mosaicked together in order to constitute the pre-flood topography. This approach was possible because the LiDAR acquisition followed the studied flood, without that other morphogenic events occurred. In fact, we could also use the LiDAR from the past year to build the pre-flood state, but occurrence of several floods before studied period made us consider that post-flood LiDAR was more representative of the initial topography of the river. However, post-flood LiDAR acquisition took place at the end of the summer, mass failures could also have occurred due to river dewatering, which may have modified bank profiles without floods. Thus, eroded areas could be overestimated by this comparison, but at the scale of the observed bank retreat this potential amount of sediment is considered to be negligible. Comparison of pre and post-flood states is presented in figure 9 , the TIN model based on bathymetric and photogrammetry cloud of points overlay LiDAR Digital Elevation Model (DEM). Four cross-sections were extracted from both DEM and superposed in order to show the morphological evolution of the river bend:

- first cross-section shows that pre-flood profile is well fitted to post-flood profile at the upstream part of the meander. This shows that no lateral erosion occurred during the studied period on this area;

- this was also the case at the end of the river bend, downstream the last cross-section. This confirms that TIN elevation is well adjusted to the LiDAR DEM and validates the accuracy of data acquisition and of the TIN construction process;

- intermediate cross-sections also show a good fit between field measurements and LiDAR acquisition when comparing floodplain elevations. The fact that not morphological evolutions are observed between pre and post-flood states at the TIN extremities ensures that field surveys extends enough upstream and downstream of the studied area.

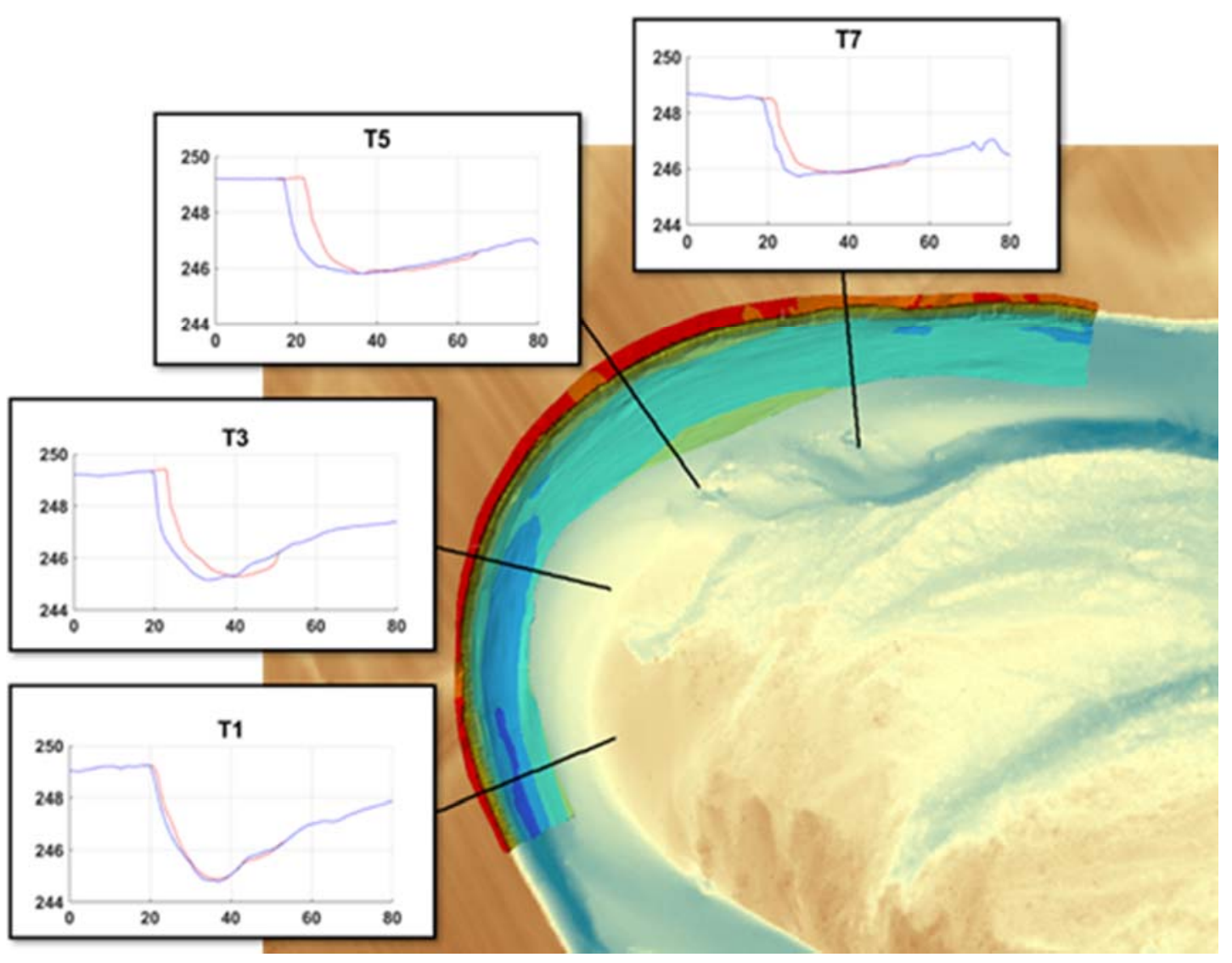

Figure 9: Extracted cross-sections of pre-flood TIN model and post-flood LiDAR DEM of the meander bend. 
As presented in figure 9, maximal bank retreat was observed in the bend apex where approximately $4 \mathrm{~m}$ of bank material was eroded. Bathymetric survey contributes to study the morphological evolution of the river bed throughout meander lateral migration. Regardless to the cross-section position, results show that river depths remain relatively unchanged with the development of the meander bend. The deepest and shallowest sectors were respectively located at the upstream and downstream extremities of the studied sector, which is in accordance with a pool-riffle fluvial forms. In fact, riffle areas are generally located at bend inflections and spatial distribution of this geomorphological units remains relatively constant over time. Although, meander shifting dynamics does not appear to modify cross-sections shape, sediment deposition rates at the convex bank seems to be longitudinally distributed. Indeed, the amount of sediment deposited at the middle and the tail of this bank (cross-sections T5 and T7) is significantly lower than at his head (cross-section T3). These dynamics are associated with the progradation of the point bar head to the downstream direction as the meander bend develops. As highlighted by a step of a few centimeters at the junction between pre and post-flood states (cross-section T3), the progradation of bar head leads to overestimate the bar head elevation at the pre-flood state. Indeed, without photogrammetric or bathymetric data, the initial topography of the emerged convex bank was characterized by data acquired during LiDAR surveys. This local topographic extrapolation could change flow patterns modelling which could influence sediment transport results. Therefore, we suggest to conduct at the same time photogrammetric monitoring over the concave and the convex banks in order to survey the morphological evolution of the entire meander bend. They are other elements that could impact results of hydro-morphological modelling such as log-jams or riparian vegetation (Eschbach, under review). Fortunately, prior to the beginning of this study, a ten-year flood removed all log-jams of the meander bend, so that hydraulic effects of log-jams became negligible.

\section{CONCLUSION}

This project located on a particularly active meander of the Moselle River is part of a larger project that extends over the "Wild Moselle" nature reserve. The accurate 3D information acquired over several periods allows to follow the evolution of the banks in a particularly accurate way. The implementation of the drone, coded targets and GPS allows the acquisition of data for the monitoring of the banks in only a few hours.

Data processing needs the same time laps, and the process put in place as well as Matlab workflow now makes possible to generate profiles and calculate volumes of bank erosion automatically. It is thus that such a project makes it possible to meet specialists from different fields, including topography and cartography with those of fluvial geomorphology.

\section{PERSPECTIVES}

A great amount of data has been acquired in recent years to study the Moselle River.

3D treatments play a fundamental role in modelling the knowledge of hydro-morphological phenomena.

The temporal dimension is also of crucial importance, especially in a context of high river morphodynamics. All data will be useful to build, calibrate and validate a 2D hydraulic and morphosedimentary model, to propose scenarios of management and restoration of the lateral mobility of the Moselle River.

\section{AKNOWLEDGEMENTS}

This study has been funded by the Water Rhine-Meuse Agency, the Region Grand Est (France) and the INSA Strasbourg, engineering school (department for civil engineering and surveying).

The authors would like to thank Ordnance Survey GB (www.ordnancesurvey.co.uk) and 1Spatial (www.1spatial.com/) for sponsoring the publication of this paper.

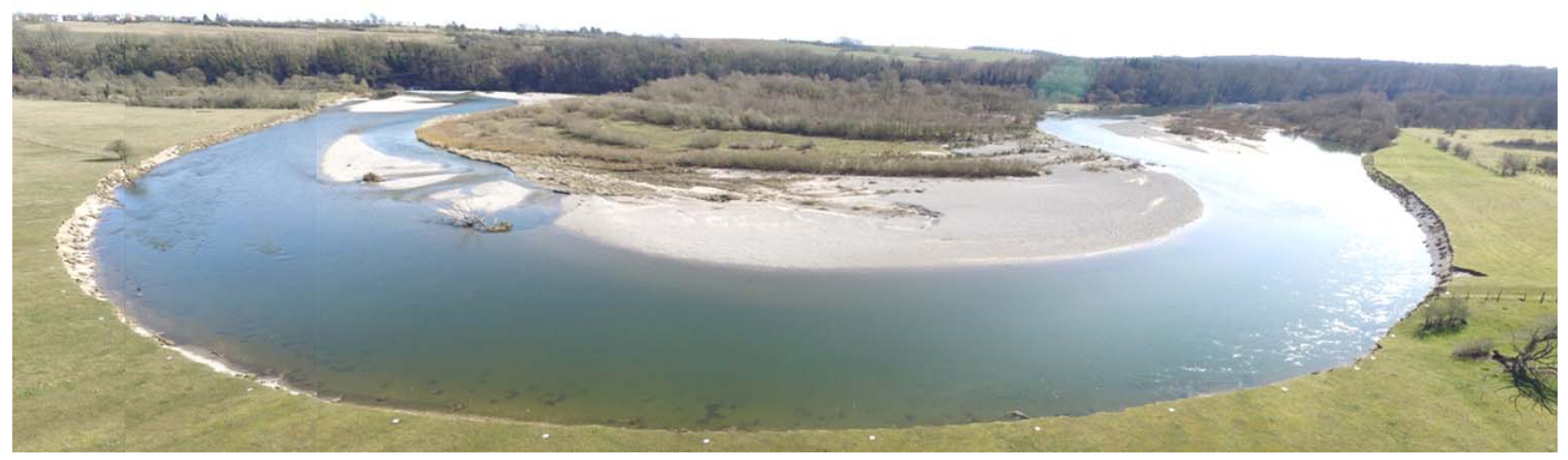

Figure 10: Stitched panoramic image of the studied meander (2019-03)

\section{REFERENCES}

Berni, J. A. J., Zarco-Tejada, P. J., Su_arez, L., and Fereres, E., 2009. Thermal and narrowband multispectral remote sensing for vegetation monitoring from an Unmanned Aerial Vehicle. In: IEEE Transactions on Geoscience and Remote Sensing, 47(3), pp. 722-738.

Casella, E., Rovere, A., Pedroncini, A., Strark, C. P., Casella, M., Ferrari, M., and Firpo, M., 2016. Drones as tools for monitoring beach topography changes in the Ligurian Sea (NW Mediterranean). In: Geo-Marine Letters, 36: pp. 151-163.

Dawod, G., Mirza, M., Al-Ghamdi, K., Elzahrany, R., 2014. Projected impacts of land use and road network changes on increasing flood hazards using a 4D GIS: A case study in Makkah metropolitan area, Saudi Arabia. In: Arab J Geosci (2014) 7:1139-1156. DOI: 10.1007/s12517-013-0876-7

Eschbach, D., Grussenmeyer, P., Koehl, M., Guillemin, S., Schmitt, L., under review. Combining geodetic and geomorphic 
methods to monitor restored side channels: feedback from the Upper Rhine.

Hamshaw, S., D., Engel, T., Rizzo, D., M., O’Neil-Dunne, J. and Dewoolkar, M., 2019. Application of unmanned aircraft system (UAS) for monitoring bank erosion along river corridors, In: Geomatics, Natural Hazards and Risk, 10:1, 1285-1305, DOI:10.1080/19475705.2019.1571533

James, M. R., and Robson, S., 2012. Straightforward reconstruction of 3D surfaces and topography with a camera: Accuracy and geoscience application, In: J. Geophys. Res.,117, F03017, doi:10.1029/2011JF002289.

Jaud, M., Delacourt, C., Allemand, P., Grandjean, P., Ammann, J., Cancouët, R., Deschamps, A., Varrel, r., Cuq, V., and Suanez, S., 2014. DRELIO : Un drone hélicoptère pour le suivi des zones littorales. In: Revue Paralia, 7: s02.1-s02.12.

Lague, D., Launeau, P., Michon, C., Gouraud, E., Juge, C., Gentile, W., Crave, A., and Hubert-Moy, L., 2016. Le LiDAR aéroporté topo-bathymétrique pour la caractérisation et le suivi des corridors fluviaux : premiers résultats et perspectives. Journée Tehnique Avancées, apports et perspectives de la télédétection pour la caractérisation physique des corridors fluviaux.

Mallet, C., Bulteau, T., Maugard, F., Rosebery, D., Garnier, C., Mugica, J., Ayache, B., Hoareau, A., Bernon, N., Paris, F., and Nicolae Lerma, A. (2018). L'observatoire de la côte aquitaine : bases de données pour la compréhension des évolutions géomorphologiques. Journées Nationales Génie Côtier - Génie Civil 2018.

Murtiyoso, A., Koehl, M., Grussenmeyer, P., Freville, T., 2017. Acquisition and processing protocols for UAV images: 3D modeling of historical buildings using photogrammetry. In: ISPRS Annals of the Photogrammetry, Remote Sensing and
Spatial Information Sciences, Volume IV-2/W2, 2017, pp. 163170. doi:10.5194/isprs-annals-IV-2-W2-163-201

Nagle, D. B. and Wright, C. W. (2016). Algorithms used in the airborne LiDAR processing system (alps). In: U.S. Geological Survey Open-File Report 2016-1046.

Nex, F., Remondino, F., 2014. UAV: platforms, regulations, data acquisition and processing, in: Remondino, F., Campana, S. (Eds.), 3D Recording and Modelling in Archaeology and Cultural Heritage: Theory and Best Practices. Archaeopress, Oxford, England, pp. 73-86.

Pfeifer, N., 2007. Overview of TLS systems, overall processing and applications. ISPRS summer school 2007, 47(3): pp. 722738 .

Remondino, F., Barazzetti, L., Nex, F., Scaioni, M., Sarazzi, D., 2011. UAV photogrammetry for mapping and 3D modeling Current status and future perspectives. In: Int. Arch. of the Photogrammetry, Remote Sensing and Spatial Information Sciences, Volume XXXVIII-1/C22, 2011, pp. 25-31.

Rivas Casado, M., Ballesteros González, R., Ortega, J. F., Leinster, P. and Wright, R., 2017. Towards a Transferable UAVBased Framework for River Hydromorphological Characterization. In: Sensors 2017, 17, 2210, 22 pages. doi:10.3390/s17102210

Watts, A. C., Ambrosia, V. G., and Hinkley, E. A. (2012). Unmanned Aircraft Systems in remote sensing and scientfic research: classification and considerations of use. In: Remote Sensing, 4: pp. 1671-1692.

Watanabe Y., Kawahara Y., 2016. UAV photogrammetry for monitoring changes in river topography and vegetation. In: Procedia Engineering 154 (2016), pp. 317 - 325. doi: 10.1016/j.proeng.2016.07.482 